\title{
The Impact Of Sustainability On Global Trade: A Cross-Curricular Project
}

Curt M. Weber, J.D., University of Wisconsin-Whitewater, USA

Sharon Roy, M.B.A., University of Wisconsin-Whitewater, USA

\begin{abstract}
One of the challenges in higher education is leading students in the application of information from one course to learning material in subsequent coursework. The authors have devised a joint project for courses in Logistics and Administrative Law to assist students in correlation of material in courses of two business majors, with emphasis on sustainability and college-identified core competencies. Goals and construction of the project are discussed, with post-project feedback from students participating in the project, and assessment by the authors.
\end{abstract}

Keywords: Logistics, sustainability, administrative law, cross-curriculum learning, international business, core competencies, assessment

\section{INTRODUCTION}

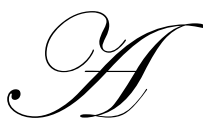

mong the challenges of teaching at the postsecondary level, indeed, at any level of education, is the guiding of students toward integration of subject matter. This challenge is significant enough within the immediate subject of a given course, but substantially increases when crossing curriculum ${ }^{1}$. The research of Edgar Dale shows that after two weeks, we tend to remember $10 \%$ of what is read, $20 \%$ of what has been heard, $30 \%$ of what we see, and $90 \%$ of what we say and do. ${ }^{2}$ The authors devised and implemented an exercise to utilize the strengths of their respective classes in a study of sustainability practices in international trade, relevant to upper level business students.

\section{ORIGINS OF THE GLOBAL TRADE PROJECT}

The College of Business and Economics (CoBE) of the University of Wisconsin-Whitewater, is accredited by the Association to Advance Collegiate Schools of Business (AACSB). ${ }^{3}$ CoBE has as one of its goals to make its students "more conscious of our environmental footprint, and to equip these students with skills to minimize this footprint." " This commitment is embodied in the CoBE membership in the Association for the Advancement of Sustainability in Higher Education (AASHE). ${ }^{5}$ Among its initiatives in sustainability, the University of WisconsinWhitewater each semester offers Project Savanna, designed to incorporate sustainability into existing courses. ${ }^{6}$ The authors were participants in the first offering of the Project during the Fall 2009 semester. Among the exercises during this Project was to explore potential collaboration between instructors; the germination of the project which is the subject of this paper occurred during this Project Savanna exercise. To the authors' knowledge, this is the first such collaborative effort to have been spawned by Project Savanna. The courses involved in the project were

\footnotetext{
${ }^{1}$ David Laughton, Roger Ottewill, Developing cross-cultural capability in undergraduate business education: implications for the student experience, accessed at http://www.emeraldinsight.com/10.1108/00400910010378467.html

2 Edgar Dale, Audio-Visual Methods in Teaching (3d Ed.), Holt, Rinehart, and Winston (1969), available at http://ww.cals.ncsu.edu/agexed/sae.ppt1/sld012.html

${ }^{3} \mathrm{http}: / /$ www.AACSB.edu.html

4 http://www.uww.edu/sustainability.html

5 http://www.AASHE.org.html

${ }^{6}$ http://www.uww.edu/sustainability/academics.html
} 
Logistics $^{7}$ and Corporate Governance and Administrative Law. ${ }^{8}$ Both courses had been recognized by CoBE as expressly incorporating sustainability. ${ }^{9}$

In the course of their discussion during Project Savanna, the authors made a preliminary assessment of the skill sets of their respective classes: the Logistics students brought the ability to assess various modes of transportation, while the Corporate Governance students would provide knowledge of the regulatory process. ${ }^{10}$ In addition, students in both classes had completed Business and Commercial Law, which includes acquiring skills in on-line legal research. ${ }^{11}$

Devising the exercise was a relatively straightforward task, accomplished with a limited amount of strain, following an easily replicated protocol. The exercise was designed to be in conformance with the following elements:

- $\quad$ A topic that lends itself to study from several points of view;

- $\quad$ Two to five valuable themes or essential questions that the instructors want to be explored by the students;

- Approach and activities to further students' understanding more than is possible in a traditional, single discipline unit. ${ }^{12}$

There were two approaches to curriculum integration considered:

- $\quad$ INTERDISCIPLINARY APPROACH Interdisciplinary skills are the organizing center for multiple subject areas; these are process skills, such as research, literacy, and numeracy. Connections are also made with content through the teaching of concepts that cut across subject areas.

- $\quad$ TRANSDISCIPLINARY APPROACH Often project-based, students act as the organizing center. This approach is based on the premise that most or all disciplines are embedded in the topic of study and can be isolated, if so desired. ${ }^{13}$

The transdisciplinary approach was selected for this exercise.

Discussion ensued as to project goals and competencies to be included. The immediate goal, of course, was increased awareness of the environmental footprint of moving a commodity. Mindful that there should be several valuable themes and/or essential questions, and to further challenge students to analyze conditions, goals, and practices, the decision was made to overtly encourage students to move to the second step of sustainability, that is, the skills to minimize the environmental footprint. The exercise thus adopted the holistic definition of sustainability of the AASHE, "encompassing human and ecological health, social justice, secure livelihoods, and a better world." " To this end, the students would consider the importation process and its impact on the country of

\footnotetext{
7 "MARKETNG 442 LOGISTICS Analysis of the problems encountered in the physical movement of goods from the end of production to the consumer. Surveyed in this course are various techniques and methods for analyzing spatial arrangements of markets, plant and warehouse location, inventory systems, election of carrier alternatives and selection of physical movement channels." Accessed at http://wicits.uww.edu/sustainability/classes.html

8 "FNBSLW 455 CORPORATE GOVERNANCE AND ADMINISTRATIVE LAW ...The course explores business, financial, political, ethical and legal issues affecting systems by which corporations are directed and controlled. Students will examine...the internal and external architecture of corporate governance... as well as corporate culture, corruption, management and board compensation, sustainability, and conceptions of social responsibility." Accessed at http://wicits.uww.edu/sustainability/classes.html

${ }_{9}^{9}$ http://wicits.uww.edu/sustainability/classels.html

${ }^{10}$ The students had studied the American regulatory structure in some depth, and compared this system to civil law systems, other common law nations, and international law.

${ }^{11}$ http://libguides.uww.edu/fnbslw341

12 J. L. McBrien and R. S. Brandt, The Language of Learning: a Guide to Education Terms, p. 55, Alexandria, VA: Association for Supervision and Curriculum Development

13 Franzie L. Loepp, Models of Curricular Integration, The Journal of Technology Studies, p. 4, accessed at http://scholar.lib.vt.edu/ejournals/JOTS/Summer-Fall-1999/Loepp.html

${ }^{14}$ http://www.AASHE.org/about.html
} 
origin as well as on the destination, considering local and national implications. This coincides with the questions Beane presents in his curriculum planning:

1. What questions and concerns do you have about yourself?

2. What questions and concerns do you have about your world? $?^{15}$

The exercise, simply titled "Global Trade Assignment" and attached a Appendix 1, requires students, organized into groups, to determine sources of a product, the most viable source of that product, and how to most effectively transport the product to Chicago, Illinois. ${ }^{16}$ The analysis is to include financial, environmental, and public relations costs, including currency exchanges. The work was divided into eight writing assignments, and an in-class oral presentation.

The exercise was further intended to address competencies identified as essential in the workplace:

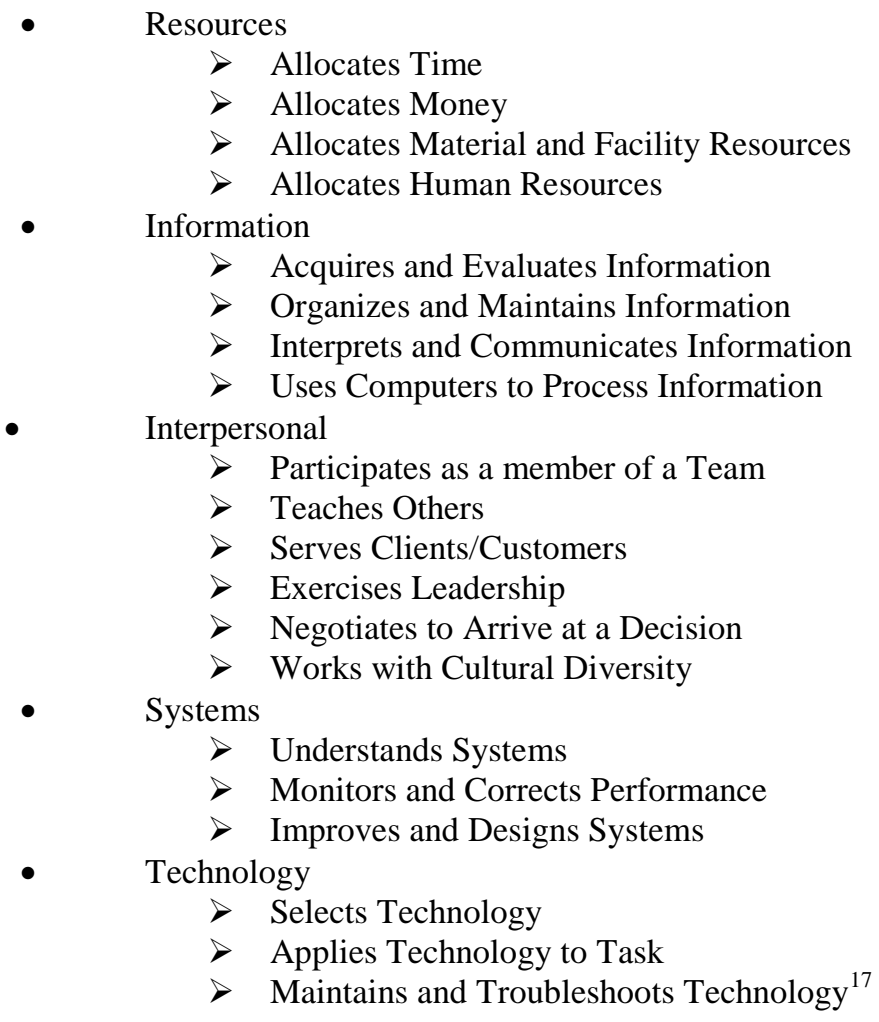

This exercise, through its nine components, addressed each of these competencies.

The authors opted to use various spices as commodities to be imported. The selection was made for several reasons, including:

\footnotetext{
15 James Beane, A middle school curriculum: From rhetoric to reality (1993). Columbus, OH: National Middle School Association, cited in Overview of Curriculum Integration, accessed at http://www2.yk.psu.edu/ jlg18/506/ci over.pdf

${ }^{16}$ While the product ultimately would be transported to Beloit, Wisconsin, the authors recognized that because there would be effectively only one mode of transportation, i.e., trucking, available for the final leg to Beloit Wisconsin, it would be advisable to eliminate that leg as lacking the analysis required for the remainder of the journey. Nevertheless, some students took the initiative to include this leg in their analysis.

${ }^{17}$ Secretary's Commission on Achieving Necessary Skills, Skills and Tasks for Jobs - A SCANS report for America 2000 , U. S. Government Printing Office, accessed at http://www.arp.sprnet.org/curric/scans.htm;
} 
- $\quad$ Relative uniformity of containerization and modes of transportation

- $\quad$ Students' familiarity with the commodities

- $\quad$ Direct connection with a local business

This last factor became a key element. One of the largest businesses in the vicinity of the University of Wisconsin-Whitewater is Kerry Ingredients \& Flavours, ${ }^{18}$ American subsidiary of Kerry Group plc, ${ }^{19}$ headquartered in Beloit, Wisconsin, approximately thirty miles (forty-eight kilometers). Through her prior work in private industry and her current academic endeavors, one of the authors had professional contacts with several managers at Kerry ingredients \& Flavours; their input on this project was invaluable. They identified several spices extensively used by Kerry in its products.

The exercise was distributed to the students during the second week of class, and was further made available on the website for each class, via Desire2Learn. ${ }^{20}$ Anticipating some resistance to the project on the part of some students, the exercise specifically described the goal of "a marketable expertise for further study in international business."

It was, of course, important to allow each course to meet its other learning objectives, thus, the exercise was conducted over a period of approximately seven weeks. The timeline for the various components of the exercise was included on Desire2Learn; wherever possible, only one written assignment would be due in that week.

\section{IMPLEMENTATION OF THE PROJECT}

Students were divided into fifteen groups, with each group consisting of at least one Corporate Governance and Administrative Law student, and two or more Logistics students, to cultivate the synergies of the disciplines involved. Where feasible, students organized their own groups; the instructors set up the remainder of the groups randomly. ${ }^{21}$ At the time the groups were established, each group was (again) randomly assigned a spice.

In addition to the respective course's Desire2Learn website, the University librarian assigned to the CoBE set up a research guide on the University library website, ${ }^{22}$ with the categories of Country Profiles, Trade Resources, and Resources Recommended by Clients to guide the students' online research. The students, of course, were not limited to these resources; the list provided reputable sources for student research. The classes met jointly at the onset of the project for a presentation in the computer lab by the University librarian to acclimate the students to the resources available; the list of sources grew during the exercise. At the request of the students, additional joint sessions were held in the computer labs, during which the authors and librarian guided student groups engaged in their research.

The initial presentation by an industry special occurred early in the exercise, again at a joint class meeting. A representative from an international food and spice broker, James A. Kuzma of Henry Broch and Company, ${ }^{23}$ who works with Kerry Ingredients \& Flavours, met with the students to give an overview of spice importation and some of the challenges attendant thereto. He had been made aware of what spices the groups were researching, and brought samples of those spices to the class. He answered student questions as to those spices, ${ }^{24}$ and importation into the United States. He further offered to make himself available throughout the project, answering students' emailed inquiries. He responded to at least twenty-two such inquiries, copying the authors on correspondence with the students. This continuing correspondence covered such varied subjects as political climate of a specific nation,

\footnotetext{
${ }^{18} \mathrm{http}: / /$ www.kerry.com

19 http://www.kerrygroup.com

${ }^{20} \mathrm{http} / / /$ www.uww.edu/desire2learn

${ }^{21}$ One challenge met by the authors was that she had two sections of the Logistics course, only one of which had a meeting time that coincided with the time of the Corporate Governance and Administrative Law course; the second section of the Logistics course met at 8:00 A.M. Several of the Corporate Governance students graciously volunteered to work with groups from this early section, so that no one was involuntarily assigned to an early group.

${ }^{22} \mathrm{http}: / /$ www.libguides.uww.edu/marketing442 and http://www.libguides.uww.edu/fnbslw455

23 http://www.hbroch.com

24 The questions included the oft-asked, "What's it for?"
} 
and ease of conducting business in a specific nation, and spice quality; this latter concern involved physical, chemical, and microbiological specifications. In addition, his initial presentation addressed identifying legal requirements, particularly return of funds. ${ }^{25}$ This not only emphasized the necessity of following protocol to avoid unnecessary complications in the importation process, it also helped bolster the relevance of the exercise to the students in the corporate Governance and Administrative Law course. In an e-mail to the authors, Mr. Kuzma remarked that it was his hope that "in some small way we were able to close the gap between the rigors of the classroom and the practical application of the global spice trade." 26 There is little doubt that he succeeded.

Further presentations were held for the joint classes, involving managers from Kerry Ingredients \& Flavours; the slides from these presentations were subsequently posted on the respective class's D2L websites. ${ }^{27}$ Subjects included an overview of Kerry Group, basic importation requirements, and Kerry's sustainability policy and program. To stimulate consideration of sustainability issues, slides were also posted with respect to the Overview of Seaport Environmental Program and the Clean Air Strategy of the Port of Seattle, Washington. ${ }^{28}$ One of the authors had acquired these slides during a prior research project.

The writing assignments included a SWOT analysis ${ }^{29}$ and executive summary, in addition to traditional written assignments. The intention was for students to be exposed to the types of written work they would be expected to encounter in their professional lives. The multiple assignments were designed to keep students "on track" during the pendency of the exercise, to reduce the magnitude of the exercise, and to provide feedback in an effort to raise the quality of the students' work product. Assignments were submitted electronically to the instructor specified, who then assessed the work. Division of the assessment was designed for the students to receive input from the instructor whose expertise fit that particular element. Students had been notified in the handout of the value of each assignment. The assignments were ordered in such a fashion as to avoid one instructor being bombarded with submissions while the other waited for his or her assignments to be submitted.

After the final assignment had been graded, the groups were required to submit a portfolio of their work from the exercise, and to prepare a slide presentation to be shared with the classes at a joint meeting. Each student was required to participate in the class presentation. The presentation was to last no longer than ten minutes, ${ }^{30}$ with assessment by the authors. The rubric for the presentation was on a 100-point system:

30\% Presentation - Presentation should be organized; PowerPoint should be used as bullet points; clear main points should be evidenced and effective eye contact and confidence should be displayed by all members. No more than 10 minutes can be used for the presentation. Professional attire is required.

30\% Research - Mastery of using and understanding multiple sources of primary and secondary research and proper documentation of these sources. Sources such as guest speakers and alternate sources that were not on the study guide should be included. A list of sources from most frequently used to least frequently used must be submitted.

40\% Thinking and Analyzing - Students need to clearly demonstrate that they understand the "so what" "this means" of this international trade assignment. Recommendations on how to improve the supply chain, stay ahead of regulatory issues and the importance of quality and communication in importing goods to the US. The decisions that you have made during this process will have to be supported in a logical, realistic and intelligent manner. An Executive Summary must be part of your two-page narrative.

The rubric sheet contained ample space for instructor comments.

\footnotetext{
${ }^{25}$ James Kuzma, unpublished e-mail of February 5, 2010.

${ }^{26}$ James Kuzma, unpubished e-mail, February 10, 2010.

${ }^{27}$ Ibid.

${ }^{28} \mathrm{http} / / /$ www.portseattle.org/seatac.html

29 Strengths, Weaknesses, Opportunities, Threats

${ }^{30}$ Given the number of groups, presentations were scheduled over two class sessions.
} 


\section{RESULTS}

While there was an occasional late assignment, all student groups completed the exercise in a timely manner. ${ }^{31}$ Of the countries selected as a source, most coincided with the nations currently used by the spice broker. It is doubtful that the information presented by the broker did not influence the decisions made, but a majority of the student groups did provide their own analysis as to why one nation was superior to another with respect to the same spice. One disappointing aspect was that, while the instructors had corrected grammatical errors in the assignments, some groups handed in final products with those same mistakes.

Most, if not all, groups considered air transportation as part of the importation process. While no group recommended air transit, based on factors of cost and carbon footprint and lack of a need to ship the commodities that quickly, some groups did seem to dwell on why they chose not to recommend air travel to such an extent that they were pressed for time to discuss the advantages of modes they were recommending. Certain groups were more creative than others in their recommendations; one group ${ }^{32}$ recommended bringing anise to the port of Savannah, Georgia, short-sea shipping to the Mississippi River Canal, thence via barge to the Port of Chicago. They were able to explain cost-saving realized as opposed to truck or rail transportation. Interestingly, this group suggested an alternate mode, anticipating weather delays in the Gulf of Mexico. This group was exceptional in suggesting such alternatives.

There were some shortcomings in the students' analyses. For example, James Kuzma had advised the students to select a port of entry that regularly handled the commodity of interest to the students; "Do not choose a new port as the inspectors are not familiar with handling, testing, or moving the goods. Spice ports are NY/NJ and Long Island." ${ }^{33}$ Yet, of the fourteen groups which used water-based transportation, six chose ports other than Long Beach or a New York or New Jersey port. Of those six, only one group, importing nutmeg from Indonesia, gave an explanation as to why it chose Seattle over the California port of Long Beach. Interestingly, their primary concern was whether such a shipment could pass the California environmental regulations. ${ }^{34}$ Nevertheless, the SCANS Systems and Technology competencies had been adequately addressed. In the case of the aforementioned anise and nutmeg groups, the authors discerned the Technology competency attribute of monitoring and correction of performance.

During the pendency of this exercise, the United States Congress was considering "cap and trade" legislation ${ }^{35}$ regarding environmental concerns. Ultimately, the bill died in Congress. This did add a challenge to the students, as they needed to consider not only existing regulations, but also projected laws and regulations.

The business librarian, Kyle Naff, compiled an analysis of the references used by the students in their papers; the results are attached as Appendix 2. Overall, the references were of acceptable quality and credibility. The results seem to indicate that the SCANS Information competency had been met.

The competencies of Resources and Interpersonal are more challenging to assess objectively. That the work was completed, and largely on a timely basis, would seem to meet the threshold requirements of these competencies. In addition, Appendix 3 displays the results of an ungraded survey of the students. Their comments seem to indicate that the Interpersonal competency has been met, given that in all fifteen categories, the majority of responses was positive, falling in either of the "Agree" or "Strongly Agree" categories. Negative reactions, either "Strongly Disagree" or "Disagree," tended to be relatively small, ranging from zero in three cases to a high of seventee per cent in two categories.

\footnotetext{
${ }^{31}$ One group did postpone its class presentation from Monday at 8:00 A.M. to Wednesday at 8:00 A.M., of the same week.

${ }^{32}$ The anise group sourced its spice from India.

${ }^{33}$ James Kuzma, unpublished e-mail, February 5, 2010.

${ }^{34}$ Andrew Woehrer, Sarah Dahl, Melissa Smiley, "Consideration of modes of transportation: Nutmeg," unpublished manuscript, March 1, 2010.

${ }^{35}$ H.R. 2453, $111^{\text {th }}$ Cong. (2009)
} 
The authors have identified certain changes they would make in the format of the exercise. The components of the rubric could be reordered to be in a more logical sequence for the students vis-à-vis their research and assignment completion. This may cause some added inconvenience for the instructors involved, however, those hurdles should be easily overcome with advance planning. The scoring matrix could also be adjusted to recognize students having corrected errors in their preliminary work. While at least one student preferred that there be a standard deadline for all work to be submitted, such as a midnight Monday deadline, it seems that varying dates serve to address the competencies of allocation of time and human resources, as well as organizing and maintaining information.

\section{CONCLUSIONS}

The authors are satisfied with the results of this exercise, and intend to repeat it in the future. It can be replicated with other commodities, and will be influenced by changes in politics and transportation technologies, environmental concerns, illness such as the recent salmonella outbreak connected to peppercorns, ${ }^{36}$ climate, and other factors. Students were engaged in all stages of the learning process, and were able to connect their studies to practical challenges in the business world, making this an effective exercise indeed.

\section{AUTHOR INFORMATION}

Curt M. Weber, J.D., has taught at the University of Wisconsin-Whitewater since 2002, teaching Business and Commercial Law, Advanced Business and Commercial Law, labor and Employment Law, and Administrative Law and Corporate Governance. He is also involved in the teaching of international business. He earned his J.D. from Duquesne University School of Law.

Sharon Roy has been working for the UW System since 1993 teaching in the Marketing Department at UW Whitewater and UW Madison. Prior to teaching, Ms. Roy worked in Consumer Products Marketing and Research and Development as a Food Scientist and Product Manager for international companies such as Jacobs Suchard, Bongrain International, Beatrice Foods and Western Publishing. Ms. Roy holds a B.S. in Food Science from UW Madison and an MBA from UW Whitewater. Currently, Ms. Roy's primary research and teaching emphasis is in Logistics, International Trade and Sustainability.

\footnotetext{
${ }^{36}$ http://www.cdc.gov/salmonella/montevideo/index.html
} 


\section{APPENDIX 1}

\section{GLOBAL TRADE ASSIGNMENT - SPRING 2010}

\section{UW Whitewater Logistics and Administrative Law \& Corporate Governance}

This project is designed for students to develop a skill set needed to understand the challenges of the global economy including social responsibility and sustainability issues. This understanding will be the framework on making on strategically profitable and responsible international sourcing decisions. One student from Administrative Law and Corporate Government and two students from Logistics will be teamed up to complete this analysis. This is an innovative assignment that will deliver to you a marketable expertise for further study in international business. Your client is Kerry Foods, whose U.S. corporate office is in Beloit, Wisconsin; its international office is in Kerry, Ireland http://www.kerrygroup.com . They are an international leader in customized spice blends for the food industry. Three lab sessions have been scheduled with Kyle Naff, the COBE library representative to aid you in your efforts. Those lab dates are February 10, and a date to be established by Mr. Naff. Study guides and e-files to use for this project will be on your D2L sites. Mr. Naff will also be available for office hours the evening of March 14, 2009. Your first assignment is a SWOT analysis (see grading Rubric \#6) done by your country of origin. This is due to the Marketing 442 dropbox by midnight on February $10^{\text {th }}$.

This project will be presented on March 15 and March $17^{\text {th }}$. Library guides are available at http://libguides.uww.edu/marketing442 and http://libguides.uss.edu/

\section{This assignment (see attached Rubric) will be worth 200 points and will be graded on the following process:}

1) Choose one of the spices from the following list that Kerry Foods imports for their custom blends: black pepper, cinnamon/cassia, paprika, pepper hot (Jalapeno red), mustard, chili pepper (low heat), garlic powder, pepper, fennel, cumin, parsley, coriander seed, oregano, sage, aniseed, turmeric, nutmeg, rosemary.

2) Determine where the most viable source will be to obtain the spice. A SWOT analysis needs to be completed on your country of origin that considers internal and external issues such as product availability and cost, quality, QC/safety policies, political climate including trade agreements, transportation modes available, availability to ports, technology and infrastructure requirements, environmental regulations, language challenges, documentation requirements, currency stability forecast, etc.

3) Determine the modes of transportation to move the raw materials from origin to the end-user. When you make this determination, you need to assess the environmental impact, quality and efficacy in terms of maximizing customer service and the integrity of product. For this part of the assignment, you will need to research what air and water quality regulations/incentives/compliance laws will impact your decision making. The objective of this decision making is to stay ahead of government environmental compliance (on carbon emissions and other carcinogens (see Port of Seattle pdf file on D2L) and to maximize social responsibility in your tactics. You will, of course, need to consider current government regulations with respect to transportation and importation into the United States.

4) Assess what the financial, environmental and public relations costs will be of each component of the product you are importing - this information will need to be organized into spread sheet format with currency exchanges determined. Your destination should be Chicago, Illinois.

\section{GRADING RUBRIC}

1. Consideration of modes of transportation (maximum: 30 points). This will include identification of alternatives available, assessing the viability of the respective alternatives, and selecting appropriate modes.

2. Consideration of current regulations (maximum: 30 points). This will include identification of areas of regulation affecting all aspects of importation of the selected product into the United States, destination Chicago, Illinois. Assessment should also include the impact of those regulations, including security and trade issues. 
3. Consideration of the political element (maximum: 30 points). After identifying potential sources of the product, assess the benefits and drawbacks of obtaining the product from the respective nations. This will include not only those nation's political climates, but also relations with the United States, and public perceptions in the domestic market.

4. Consideration of environmental impact (maximum: 40 points). What is the environmental impact of obtaining and transporting the product to Chicago, Illinois. You are to consider sustainability, the carbon footprint, and such other factors as your group has identified as being essential to the environmental impact. This may include consideration of alternative products, such as substitution of high fructose corn syrup or sugar beets for cane sugar.

5. Consideration of future environmental regulation (maximum: 30 points). Because this is an ongoing contract, assess the effect of future environmental regulation. Consideration should be given to regulation in the exporting nation as well as the United States; "future" refers both to pending and projected regulations.

6. Analysis of considerations (maximum: 20 points). Explain why choices were made, including reasoning behind those decisions, and the sources of information and data used to derive those conclusions.

7. Communications (maximum: 20 points). Display of appropriate written and oral communications skills, and whether instructions were followed.

\begin{tabular}{|c|c|c|c|c|c|}
\hline Category & Outstanding & Very Good & $\underline{\text { Average }}$ & Below Average & $\underline{\text { Total Score }}$ \\
\hline 1 & 30 & 24 & 21 & 18 & \\
\hline 2 & 30 & 24 & 21 & 18 & \\
\hline 3 & 30 & 24 & 21 & 18 & \\
\hline 4 & 40 & 32 & 28 & 24 & \\
\hline 5 & 30 & 24 & 21 & 18 & \\
\hline 6 & 20 & 16 & 14 & 12 & \\
\hline 7 & 20 & 16 & 14 & 12 & \\
\hline
\end{tabular}




\title{
APPENDIX 2
}

\author{
Marketing 442 / Finance \& Business Law 455 \\ Sharon Roy \& Curt Weber \\ Joint Project - Importing Spices
}

Analysis of References

\section{$\underline{\text { Research Support }}$}

The joint project between the Logistics and Administrative Law classes provided students with the opportunity for a practical, hands-on experience with the importation of a spice from another country. The business librarian participated in the research process in two main ways: producing a course project guide with suggested sources (http://libguides.uww.edu/marketing442 and http://libguides.uww.edu/fnbslw455) and conducting three research sessions held during class in the computer labs. Furthermore, the Library housed the materials provided by the instructor and 'client' on reserve for easy student access.

\section{$\underline{\text { Results }}$}

The business librarian analyzed the list of references from fifteen projects and identified seven major categories of sources: government, organization, business, educational, library, book and provided (e.g. class presentations, client correspondence, etc.). This classification was done primarily by examination of the URLs provided. A breakdown of the works cited is included as an appendix.

Given the nature of the project, using sources from most, if not all, of the categories is necessary to get a true picture of how to most effectively and efficiently import spices from abroad. The project highlights the complexities of international business - ensuring that credible sources of information are used in the decision-making process is key.

\section{Observations}

- In the fifteen projects analyzed, there were 412 citations.

- $\quad$ The average number of references used in the projects came in at about 27, with a high of 67 and low of 8 .

- $\quad$ For most of the groups, government sources comprised the largest proportion of total references.

- $\quad$ Organizations also seemed to provide useful information as well, though not as much.

- $\quad$ Students didn't really take to the library databases to find much.

- Overall, the students utilized credible websites for research. There were only a few egregious exceptions (Wikipedia was cited twice), but there were also others that weren't as obvious (nationsencylcopedia.com). There could have been more instruction on the evaluation of sources that was not included originally.

\section{Appendix A}

Breakdown of Sources by Type

\begin{tabular}{cccccccc}
.gov & .org & .com & .edu & library & book & provided & total \\
\hline 7 & 4 & 2 & 0 & 0 & 0 & 0 & 13 \\
13 & 7 & 21 & 2 & 0 & 2 & 0 & 45 \\
10 & 5 & 0 & 0 & 0 & 1 & 7 & 23 \\
1 & 4 & 3 & 0 & 9 & 1 & 1 & 19 \\
6 & 2 & 11 & 0 & 5 & 0 & 0 & 24 \\
10 & 3 & 5 & 0 & 1 & 0 & 0 & 19 \\
16 & 10 & 33 & 0 & 6 & 0 & 2 & 67 \\
8 & 2 & 6 & 1 & 6 & 0 & 0 & 23 \\
12 & 8 & 8 & 0 & 0 & 0 & 0 & 28 \\
6 & 7 & 9 & 0 & 0 & 0 & 0 & 22 \\
6 & 4 & 7 & 0 & 1 & 0 & 0 & 18 \\
6 & 5 & 11 & 1 & 2 & 1 & 2 & 28 \\
3 & 1 & 1 & 0 & 3 & 0 & 0 & 8 \\
14 & 4 & 29 & 1 & 0 & 0 & 0 & 48 \\
5 & 4 & 14 & 0 & 2 & 0 & 2 & 27 \\
123 & 70 & 160 & 5 & 35 & 5 & 14 & 412 \\
\hline
\end{tabular}




\section{APPENDIX 3}

\section{Global Trade Project Student Evaluation}

Responses: 29

1. The purpose of this project was clear and beneficial.

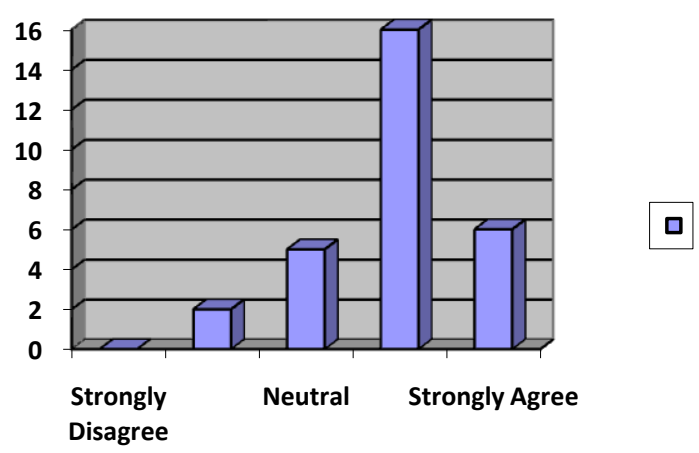

2. The skills developed during this project will be an asset to my career.

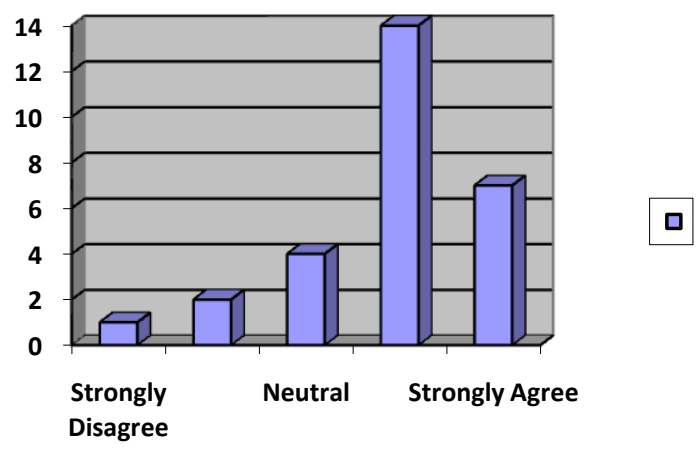

3. The process of completing the project in modules was manageable.

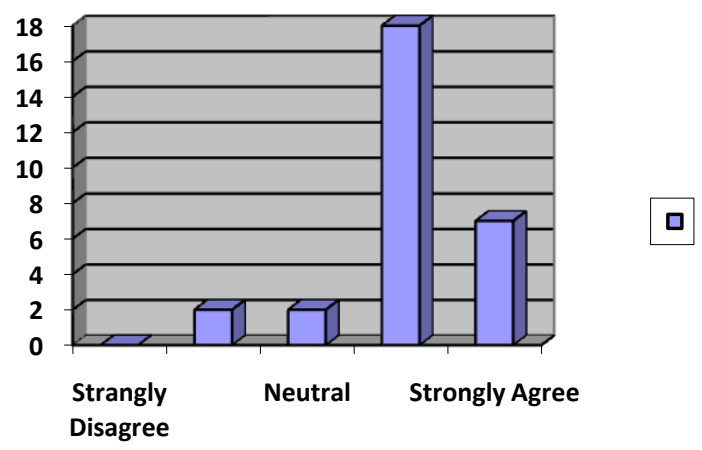


4. There was sufficient background/supplementary provided in class or on D2L.

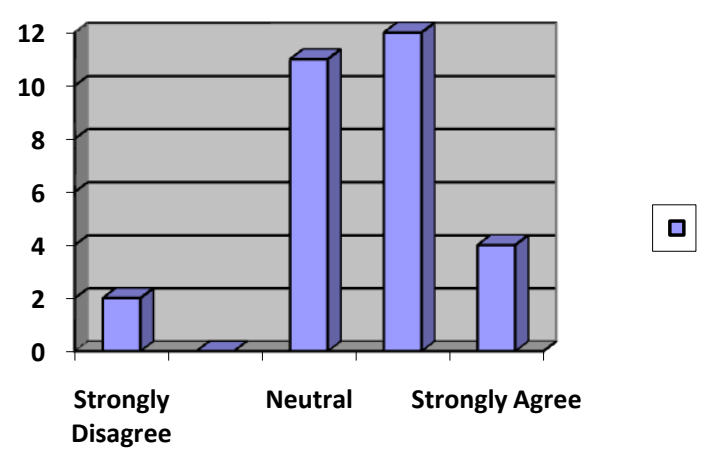

5. The project provided an opportunity to learn multiple business disciplines.

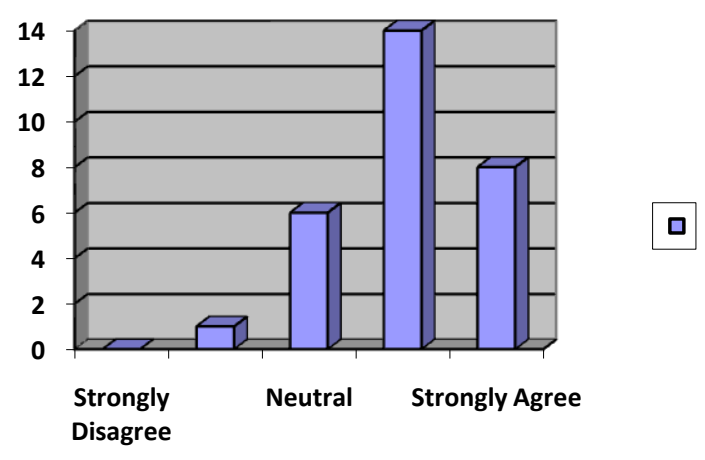

6. Feedback on the project was useful and clear.

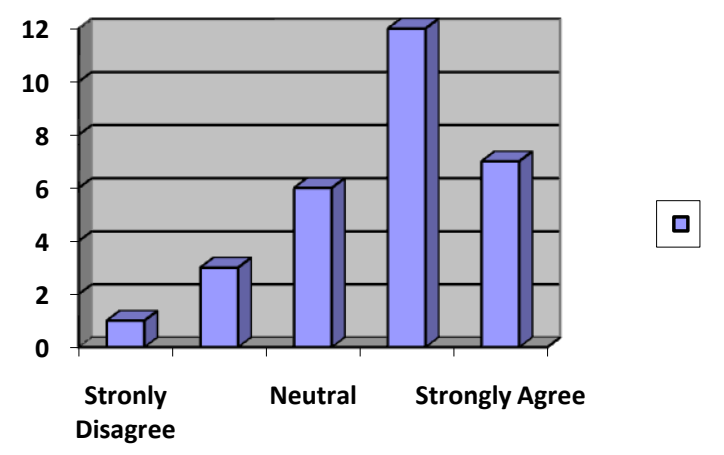

7. This project enabled me to improve my research skills.

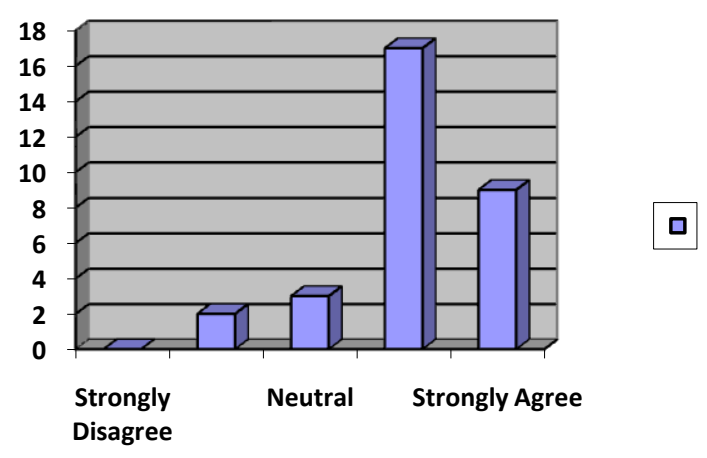


8. This project expanded my knowledge of international business.

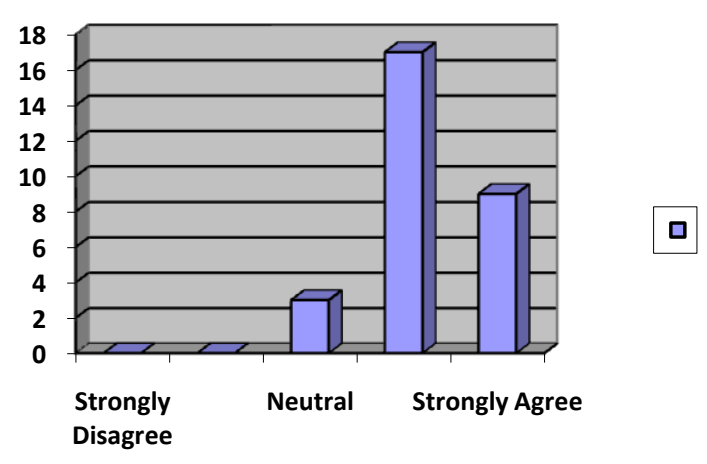

9. This project increased my understanding of current and future sustainability issues in the supply chain.

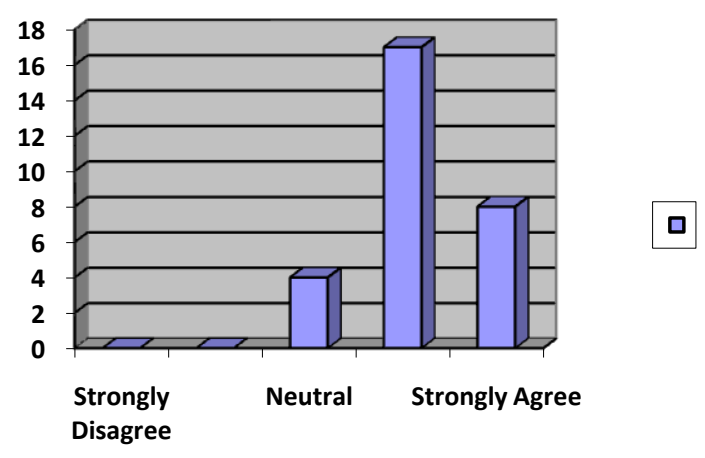

10. The guest speakers were knowledgeable and helpful in completion of this project.

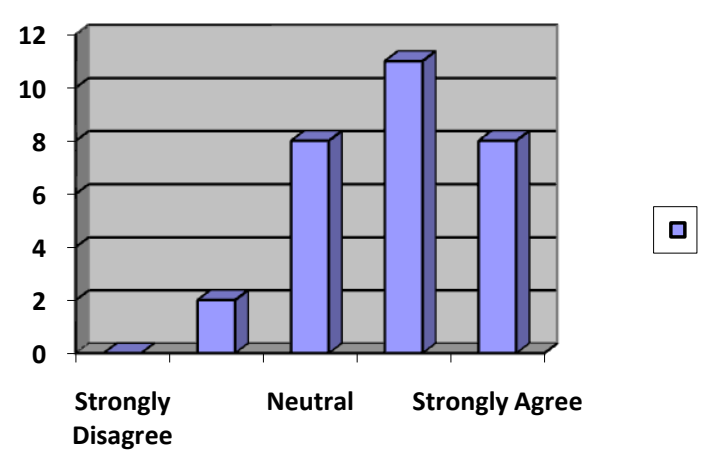

11. This project expanded my knowledge of the complexities and importance of international trade.

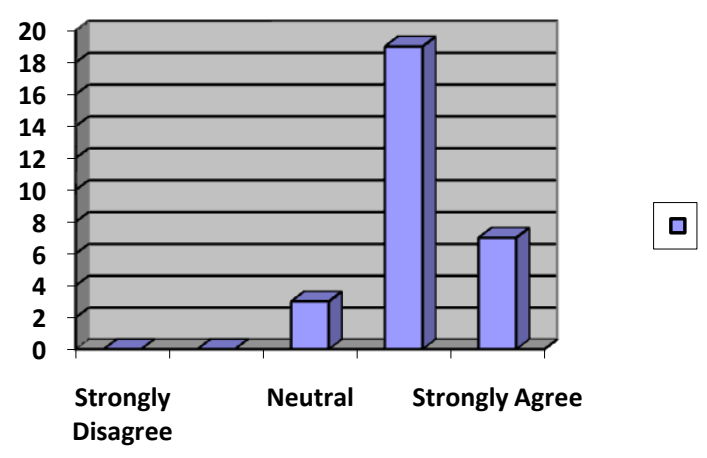


12. Our group had enough time to finish each module of the assignment.

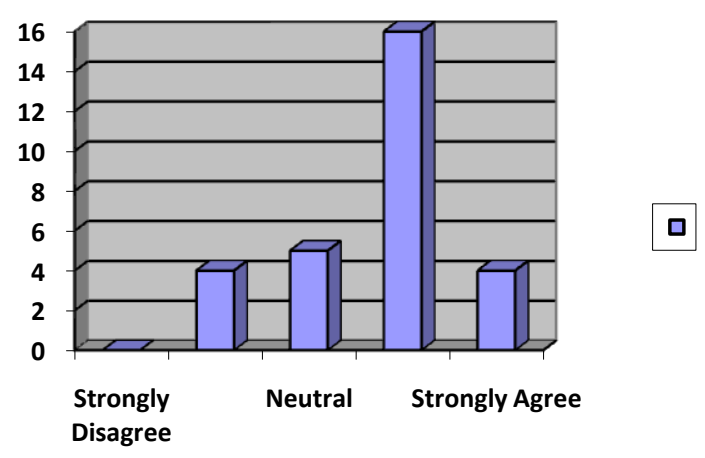

13. The entire assignment was able to be completed in a quality manner, given the timeline.

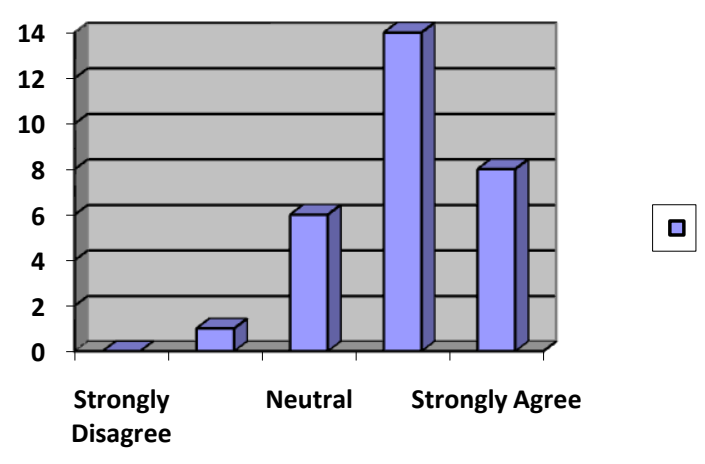

14. Working with another class was advantageous.

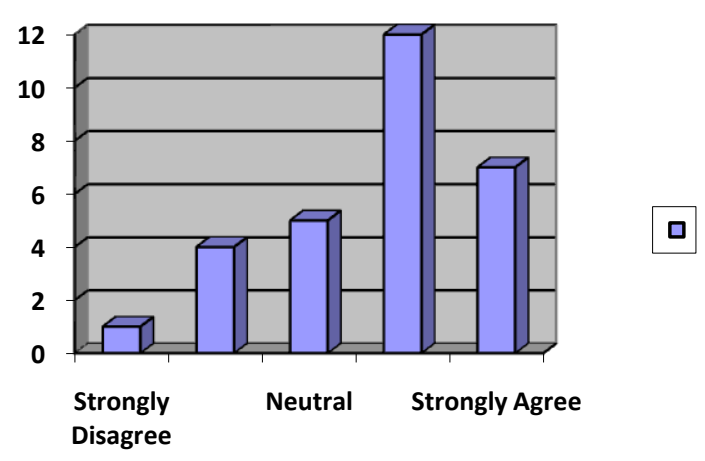

15. Working with another class expanded learning opportunities.

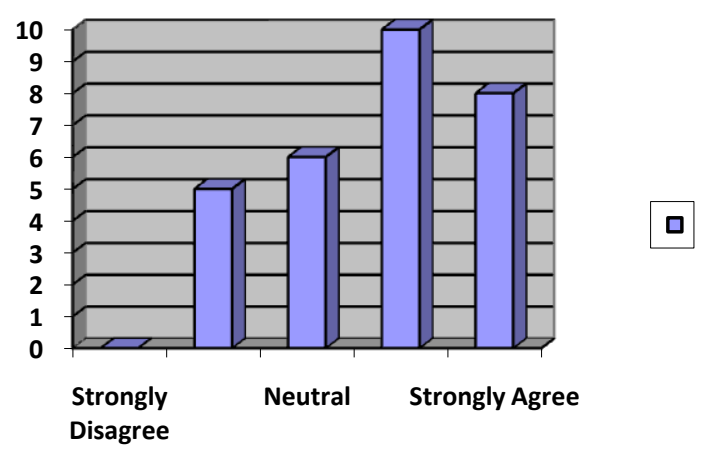

